\section{Dr. Conway et al reply}

We thank Sauret et $\mathrm{al}^{1}$ for their interest in our systematic literature review that explored potential diagnostic confusion between giant cell arteritis (GCA) and the coronavirus disease 2019 (COVID-19). This was a particularly important consideration during the early months of the COVID-19 pandemic, when community testing for SARS-CoV-2 was limited and diagnostic tests for GCA were restricted or unavailable due to redeployment of staff. ${ }^{2}$

The case reported by Sauret et $\mathrm{al}^{1}$ should be interpreted with caution. GCA is a multifactorial autoimmune disease; infections and vaccines are possible triggers, but a direct causal relationship has never been demonstrated. HLA-DRBI*04 allele carriage is common in Northern European populations; as well as being one of the genetic factors associated with $\mathrm{GCA}^{3}$ and rheumatoid arthritis, $H L A-D R B I^{*} 04$ carriage has also been linked with immunosenescence and "inflamm-aging." 4,5

Notwithstanding the temporal association described by Sauret et al, ${ }^{1}$ causal links cannot be established from isolated cases. Assuming a conservative incidence of 7 cases per 100,000 people and a population of 26 million people over the age of 50 years in a Northern European country, one would expect approximately 1820 cases per year of GCA. Assuming a random incidence within the year and and absence of causal association with COVID-19 vaccination, over 100 cases would be expected within 2 weeks of COVID-19 vaccination (Table 1). Large, population-based studies, ideally with the dates of both GCA symptom onset and GCA diagnosis, might help to determine whether the incidence of diagnosed GCA is genuinely increased during periods of mass COVID-19 vaccination, or whether patients are simply more likely to present promptly to medical care if they develop symptoms after a new vaccine (detection bias).

People-both patients and physicians - may be inclined to make sense of illnesses by making links to other elements of the medical history. In a community-based UK study of 654 patients with polymyalgia rheumatica, ${ }^{6}$ many respondents related their condition to a prior event, including personal stress, injury, infection, statins, various treatments or surgeries, insect bites, weather conditions, unaccustomed exercise, and (occasionally) influenza vaccination. However, well-designed epidemiological studies are necessary to determine whether such relationships truly exist in the population. Given the limitations associated with uncontrolled observational case reports, and the inevitability that, by chance alone, some patients will be diagnosed with new diseases after a vaccine, we must be cautious in the reporting and interpretation of cases such as this. ${ }^{1}$ Caution is especially relevant at times like these when we see variations in population vaccine uptake. Stories have power, and we must be careful to use that power wisely.

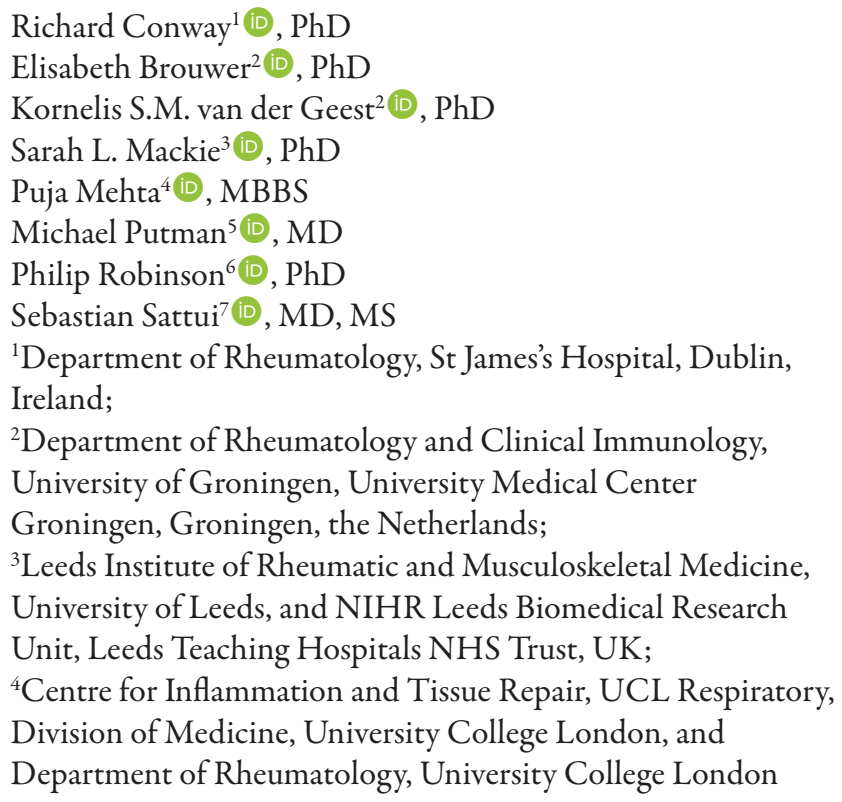

Elisabeth Brouwer ${ }^{2}$ (D), $\mathrm{PhD}$

Kornelis S.M. van der Geest ${ }^{2}$ (D), PhD

Sarah L. Mackie ${ }^{3}$ (D) PhD

Puja Mehta ${ }^{4}$ (D), MBBS

Michael Putman ${ }^{5}$ (I), MD

Philip Robinson ${ }^{6}$ (D) $\mathrm{PhD}$

Sebastian Sattui ${ }^{\circ}$, MD, MS

${ }^{1}$ Department of Rheumatology, St James's Hospital, Dublin,

Ireland;

2Department of Rheumatology and Clinical Immunology,

University of Groningen, University Medical Center

Groningen, Groningen, the Netherlands;

Leeds Institute of Rheumatic and Musculoskc

University of

Unit, Leeds

Division of Medicine, University College London, and

Department of Rheumatology, University College London

Table 1. Estimates of the number of new cases per year of various rheumatic diseases that might be expected, by chance, to present within 2 weeks of receiving a COVID-19 vaccine.

\begin{tabular}{|c|c|c|c|}
\hline Rheumatic Disease & $\begin{array}{c}\text { Annual Incidence } \\
\text { per Population Denominator }\end{array}$ & $\begin{array}{l}\text { New Cases/Year } \\
\text { in France }\end{array}$ & $\begin{array}{c}\text { New Cases/Year } \\
\text { in France Occurring by } \\
\text { Chance Within } 2 \text { Weeks } \\
\text { of COVID-19 Vaccine }\end{array}$ \\
\hline
\end{tabular}

\begin{tabular}{lccc}
\hline Giant cell arteritis & $7-10$ per $100,000^{\mathrm{c}, \mathrm{d}}$ & $1820-2600$ & $140-200$ \\
Polymyalgia rheumatica & $94.9-96.8$ per $100,000^{\mathrm{e}, \mathrm{f}}$ & $31,317-31,944$ & $2409-2457$ \\
Rheumatoid arthritis & 8.8 per $100,000^{\mathrm{g}}$ & 5896 & 454 \\
Systemic lupus erythematosus & 3.32 per $100,000^{\mathrm{h}}$ & 2224 & 171 \\
ANCA-associated vasculitis & 23.1 per $1,000,000^{\mathrm{i}}$ & 1548 & 119 \\
\hline
\end{tabular}

${ }^{a}$ Assumes the following population in France: 67 million (total); 26 million (aged > 50 yrs); 33 million (aged $>40 \mathrm{yrs}$ ); and 51 million (aged > $20 \mathrm{yrs}$ ). ${ }^{\mathrm{b}}$ Assumes a 2 -dose annual vaccine and $100 \%$ vaccination rate. ${ }^{\mathrm{c}}$ Aged > $50 \mathrm{yrs}^{\mathrm{d}} \mathrm{Mahr}$ et al ${ }^{7}(2020) .{ }^{\mathrm{e}}$ Aged $\geq 40 \mathrm{yrs}^{\mathrm{f}}$ Partington et al ${ }^{8}$ (2018). ${ }^{\mathrm{g}}$ Guillemin et al ${ }^{9}$ (1994). ${ }^{\mathrm{h}}$ Arnaud et al ${ }^{10}$ (2014). ${ }^{\mathrm{i}}$ Pearce et $\mathrm{al}^{11}$ (2016). ANCA: antineutrophil cytoplasmic antibody; COVID-19: coronavirus disease 2019. 
Hospital (UCLH) NHS Trust, London, UK;

${ }^{5}$ Medical College of Wisconsin, Milwaukee, Wisconsin, USA; ${ }^{6}$ University of Queensland Faculty of Medicine, Brisbane,

Australia;

${ }^{7}$ Division of Rheumatology and Clinical Immunology,

University of Pittsburgh, Pittsburgh, Pennsylvania, USA.

The authors declare no conflicts of interest relevant to this article.

Address correspondence to Dr. S.L. Mackie, Leeds Institute of Rheumatic and Musculoskeletal Medicine, Chapel Allerton Hospital, Leeds LS7 4SA,

UK.Email: s.l.mackie@leeds.ac.uk.

\section{REFERENCES}

1. Sauret A, Stievenart J, Smets P, et al. Case of giant cell arteritis after SARS-CoV-2 vaccination: a particular phenotype? J Rheumatol xxxxxxxxxxx.

2. Mackie SL, Brouwer E, Conway R, et al. Clinical pathways for patients with giant cell arteritis during the Covid-19 pandemic: an international perspective. Lancet Rheumatol 2021;3:e71-82.

3. Mackie SL, Taylor JC, Haroon-Rashid L, et al; UK GCA Consortium; UKRAG Consortium. Association of HLA-DRB1 amino acid residues with giant cell arteritis: genetic association study, meta-analysis and geo-epidemiological investigation. Arthritis Res Ther 2015;17:195.

4. Schönland SO, Lopez C, Widmann T, et al. Premature telomeric loss in rheumatoid arthritis is genetically determined and involves both myeloid and lymphoid cell lineages. Proc Natl Acad Sci U S A 2003;100:13471-6.
5. Thewissen M, Somers V, Venken K, et al. Analyses of immunosenescent markers in patients with autoimmune disease. Clin Immunol 2007;123:209-18.

6. Tshimologo M, Saunders B, Muller S, Mallen CD, Hider SL. Patients' views on the causes of their polymyalgia rheumatica: a content analysis of data from the PMR cohort study. BMJ Open 2017;7:e014301.

7. Mahr A, Belhassen M, Paccalin M, Devauchelle-Pensec V, Nolin $\mathrm{M}, \mathrm{Gandon} S$, et al. Characteristics and management of giant cell arteritis in France: a study based on national health insurance claims data. Rheumatology 2020;59:120-8.

8. Partington RJ, Muller S, Helliwell T, Mallen CD, Abdul Sultan A. Incidence, prevalence and treatment burden of polymyalgia rheumatica in the UK over two decades: a population-based study. Ann Rheum Dis 2018;77:1750-6.

9. Guillemin F, Briançon S, Klein JM, Sauleau E, Pourel J. Low incidence of rheumatoid arthritis in France. Scand J Rheumatol 1994:23:264-8.

10. Arnaud L, Fagot JP, Mathian A, Paita M, Fagot-Campagna A, Amoura Z. Prevalence and incidence of systemic lupus erythematosus in France: a 2010 nation-wide population-based study. Autoimmun Rev 2014;13:1082-9.

11. Pearce FA, Lanyon PC, Grainge MJ, et al. Incidence of ANCA-associated vasculitis in a UK mixed ethnicity population. Rheumatology 2016;55:1656-63. 